\title{
Evaluation of Subsurface Formation of Pabna District, Bangladesh
}

\author{
M S Islam \\ Assistant Professor, Dept. of Electronic \& Telecommunication Engineering Pabna University of Science \& \\ Technology, Bangladesh.
}

\begin{abstract}
Groundwater is a valuable natural resource and it is the most important source of irrigation water, predominant source of drinking water, and provides for most industrial needs. But large scale abstraction of groundwater creates various problems which are particularly severe for the developing countries, adversely affecting their agriculture, fishes, navigation, drinking water supply and sanitation conditions. Bangladesh is no exception to the deteriorating situation of the water resources system. So, a detailed study is needed to identify the subsurface formations which give a clear picture of the information needed, such as, the probable aquifer, its location, thickness, composition, etc.

One of the most important aspects for groundwater investigation program is the knowledge about underlying formations, i.e., subsurface formations. Borehole lithological data are important sources for obtaining information on sub-surface formation distribution. In the present work, the lithological character encountered in borehole of 303 locations have been collected, compiled, processed, analyzed and interpreted for studying the hydro-geological properties of nine upazillas of Pabna district, Bangladesh. Borehole log is one of such method that furnishes information on substrata in vertical line from the surface (Todd,1980; Clark, 1988). These furnish a description of the geologic character and thickness of each stratum encountered as a function of depth, thereby enabling aquifers to be determined. Shaded contour maps of clay, fine sand and composite sand thickness have been presented for qualitative study of groundwater potentiality of the area studied. Yield potential index map of the water saturated zone selects the suitable potential zone and hence identifies the proper location for well-sites. Stratigraphic and cross sectional views in various orientations are prepared to visualize the substance of the study area. Stratigraphy influences the formation and distribution of groundwater. It studies the surface feature of the area and plays an important role in selecting the well sites. The availability and abundance of groundwater at different places are influenced by the topographic feature.
\end{abstract}

\section{Introduction}

The development of groundwater requires knowledge of the characteristics of the subsurface water bearing zone, of which the composition and thickness are important. Seven subsurface geologic formations such as clay, fine sand, fine-medium sand, medium sand, medium-coarse sand, coarse sand and coarse sand-gravel layers are clearly identified in the study area. These formations of the area are divided into two main layers viz. upper clay layer and composite sand layer according to their water bearing potential as a top clay layer and sand layer of different grain size.

The groundwater geology of the study area has been studied. The subsurface modeling of the study area is performed by detailed study of 303 litholog data available in the study area. The thickness of the different geologic formations have been studied and presented in the form of contour maps. The maps of composite sand thickness and yield index have been presented for qualitative study of groundwater potentiality in different regions of the area studied. The 3D-stratigraphic and cross-sectional views of the investigated area have also been prepared in various profiles to assess the variation of the individual subsurface stratum in different areas. Formation and hydro-geologic parameters have also been estimated and presented in contour patterns.

\section{Materials And Methods}

Any fruitful research work does not depend not only upon the availability and quality of requisite data or information but also the appropriate methodology. It is not possible to identify and estimate the invisible properties of subsurface formations. Because it is far beyond the access of direct visual measurement and experiment. So present research work has conducted and completed through data acquisition. Analysis has been made on integrated hydro-geological approach. About 303 borehole data and static water level data of 81 locations during the period of 1994-2007 have been collected from various relevant organizations for the measurement of subsurface formations and aquifer parameters. Borehole data would provide valuable information of subsurface water bearing formations of the aquifer of the investigated area. 


\section{GENERAL FEATURE S OF THE STUDY AREA}

The study area, Pabna district, is located in the south-eastern corner of greater Rajshahi division (Fig.1). The area comprises nine upazillas covering $2371.50 \mathrm{Sq} . \mathrm{km}$. The two major rivers, the Padma and the Jamuna, are flowing along the boundaries of the study area sustaining the environmental balance and socioeconomic development (ZUP,2005). The entire study area is almost a plain land of an average elevation of $14 \mathrm{~m}$ whereas the northwestern part is slightly more elevated with maximum elevation of $22 \mathrm{~m}$. The investigated area is located in the shelf region zone of Bangladesh and was formed by the deposition of sediments carried by the river Padma and its tributaries in the Pleistocene age. The alluvium is composed of clay and sand of different grains. The overall soil quality is very much suitable for groundwater potential. The topmost formation, composed of clay and silt, is underlain by fine, medium and coarse sand. The aquifer system in the investigated area may be schematized into an aquifer of variable thickness.

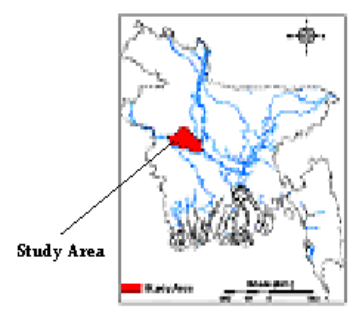

Pabura Distridt

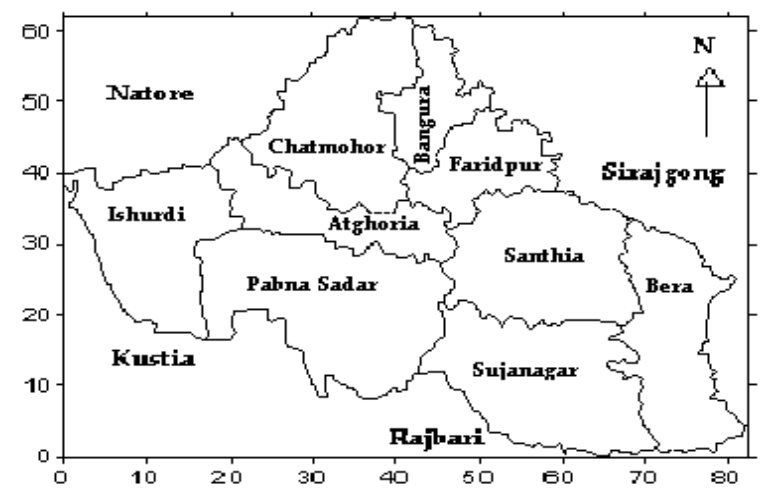

Fig.1 Representation of the study area map

III.

IV. ANALYSIS OF LITHOLOG DATA

The development of underground water requires knowledge of the characteristics of the subsurface water-bearing zone, of which the composition and thickness are essential. So, analysis of litholog data is very important. The distribution of borehole locations in the study area has been shown in Fig.2.

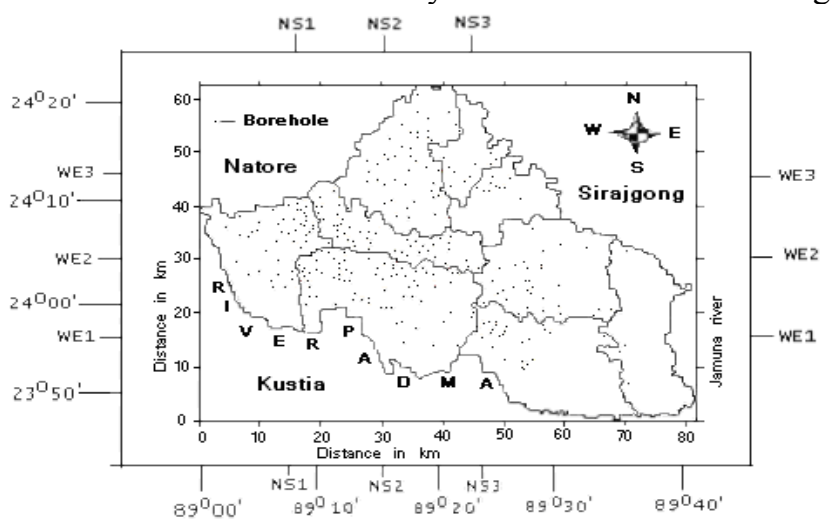

TOP CLAY LAYER

Fig.2 Area under investigation showing borehole locations

Soils of the investigated area are predominantly clay loam with a few silts at places. This clayey formation is very common in the area. The contour map of the thickness of the top clay is shown in Fig.3. In most of the area the thickness is varying in between $12 \mathrm{~m}$ to $22 \mathrm{~m}$. In some parts of the area the thickness of $22 \mathrm{~m}$ exists in discrete form. In the southeastern corner of the area the clay thickness is minimum and it is found 
below $12 \mathrm{~m}$. So the extraction of groundwater from the southeastern part of the study area would be economical if the other conditions are favourable.

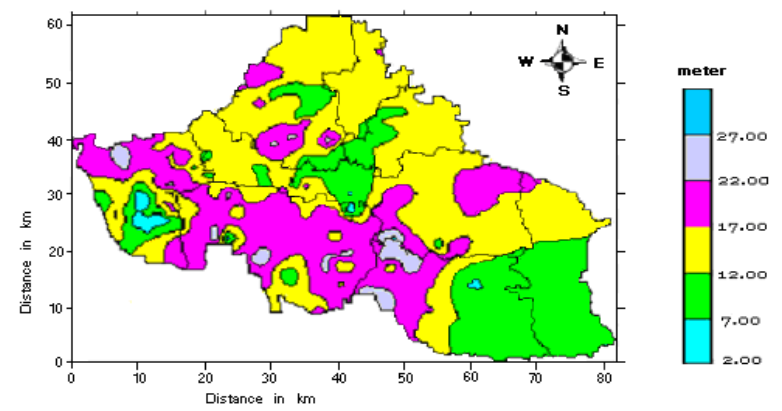

FINE SAND

Fig. 3 Contour map of the thickness of top clay (interval $=5 \mathrm{~m}$ )

The geologic formation of fine sand as the second layer is considered in the study area. The thickness of the fine sand layer has been estimated using the lithological information. A shaded contour map of the fine sand as the second layer has been prepared at $8 \mathrm{~m}$ interval with the help of available computer software as shown in Fig.4. The map shows that the thickness of the fine sand varies from 0 meter to 28 meter. The maximum portion of the investigated area ranges from $4 \mathrm{~m}$ to $12 \mathrm{~m}$. The next maximum portion ranges from $12 \mathrm{~m}$ to $20 \mathrm{~m}$ is found in the south-eastern corner of the area. A very few portions of the study area having the range from $20 \mathrm{~m}$ to $28 \mathrm{~m}$ and found in discrete distribution form and there is no continuity among them. Some areas have no fine sand as the second layer. Such portions are negligible with respect to the entire study area.

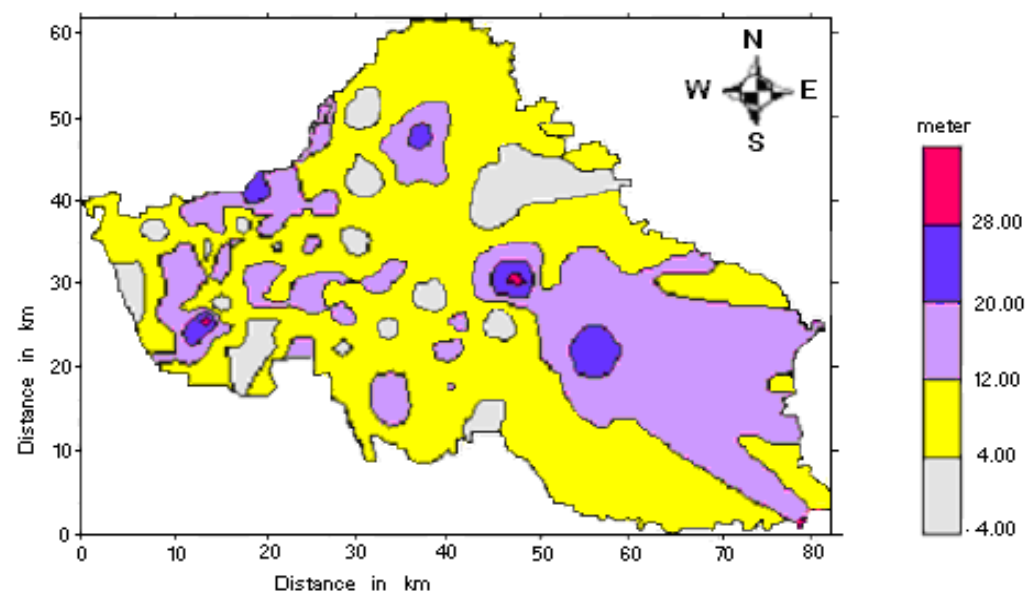

Fig. 4 Contour map of find sand thickness as the $2^{\text {nd }}$ layer (interval $=8 \mathrm{~m}$ )

\section{COMPOSITE SAND}

The thickness of the composite sand layer of the study area has been estimated using the lithological information. The combination of sand layers of different grains in the study area forms the useable aquifer which extends below the depth of $90 \mathrm{~m}$ and its thickness is undetermined from the available lithologic information. However, in the present work a shaded contour map at $4 \mathrm{~m}$ interval is prepared from the principal components of sand composition at different lithological points as shown in Fig.5.The figure shows that the thickness of the sandy formation varies between $36 \mathrm{~m}$ and $76 \mathrm{~m}$. However, it is observed that there is a trend of the sandy layer of thickness between $46 \mathrm{~m}$ and $56 \mathrm{~m}$ from the south-eastern to the north-western corner of the study area. The major portion of the study area is composed of the sandy formation of thickness between $56 \mathrm{~m}$ and $66 \mathrm{~m}$. The thickness of the composite sand in the north-eastern part and in some parts of the south-western corner ranges from $66 \mathrm{~m}$ to $76 \mathrm{~m}$. The sand thickness map of the study area reveals that this geologic formation could be treated as good groundwater reservoir. However, the north-east side is more suitable regions for groundwater potentiality. 


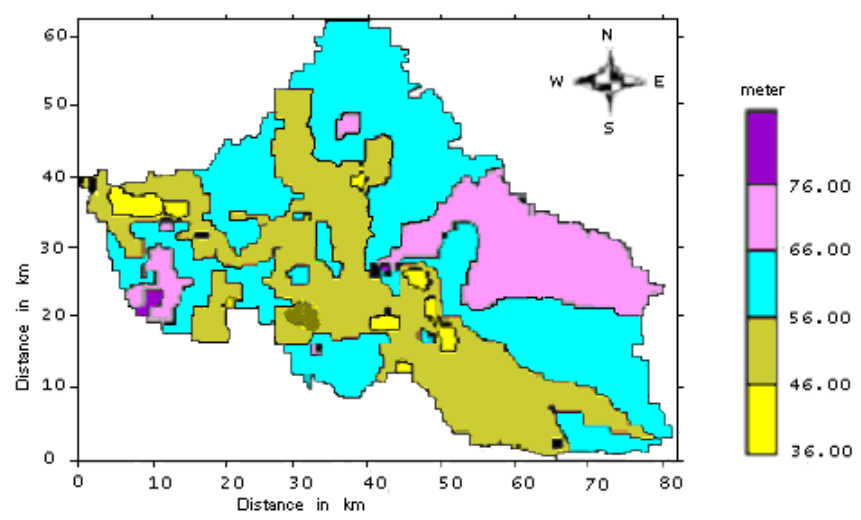

Fig. 5 Contour map of composite sand thickness (interval $=10 \mathrm{~m}$ ).

\section{YIELD POTENTIAL INDEX}

The distribution of total aquifer yield index has been processed in Fig.6. Three distinct type yield potential zones have been demarcated in the study area. The aquifer dominated high groundwater potential yield zones having values of 6 and above occupy around one-fourth of the study area. The aquitard dominated zones (almost $80 \%$ area) with yield potential index of 6 above distributed across the study area indicate a bad potentiality. The higher groundwater potential zone of yield index 11 to 21 is distributed in the south-western corner of the area. This yield potential index map is widely used for selecting the location of well sites.

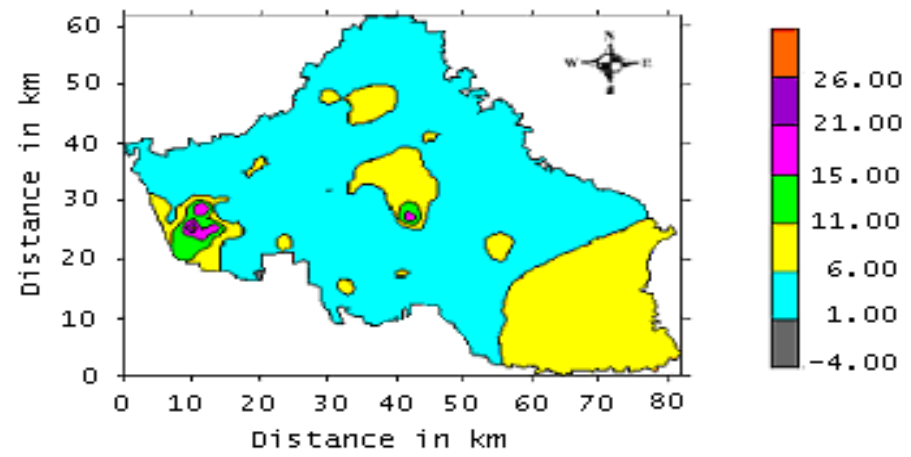

Fig.6: Distribution of yield potential index in the study area.

\section{V.}

\section{STRATIGRAPHICF VIEW}

The geologic formation is an important factor for the identification of groundwater potential zone. Stratigraphy helps to locate the position and thickness of water bearing formations and continuity of confining beds whereas structural geology helps to locate water bearing formations (Patra,2001). The distribution of aquifers and aquitards in a geological system are controlled by lithology, stratigraphy and structure of the geologic formations. The lithology is the physical make up of the sediments or rocks that form the geologic system. Unconformities are stratigraphic features of particular impotents in hydrogeology. Aquifers are commonly associated with unconformities, either in the weathered or fractured zone immediately below the surface of the buried landscape or in permeable zone in coarse-grained sediments laid down on the top of this surface. In terrain that has been deformed, aquifers would be difficult to discern because of geologic complexity.

One of the prime objectives of the present research is to assess the hydrological condition of the investigated area and to delineate the potential zone of the aquifer. For the purpose, on the basis of borehole log data, some lithological cross-sections are drawn over the investigation area.

An integrated study of the evaluation of subsurface geologic formation is useful to understand the occurrence of porous and permeable zones. The subsurface runoff is governed in part, by the geology which depends on the development of underground formations and their infiltration and transmission characteristics. So, the stratigraphy is an important tool in the search for water in areas of wide spread sedimentary rock. The position and thickness of water bearing horizons and the continuity of confining beds are of particular importance in the development of groundwater exploration zones. Three dimensional model of the individual layers of the study area have been prepared in various directions and shown in Fig.7. This model gives a clear understanding of geologic formations of the study area. 


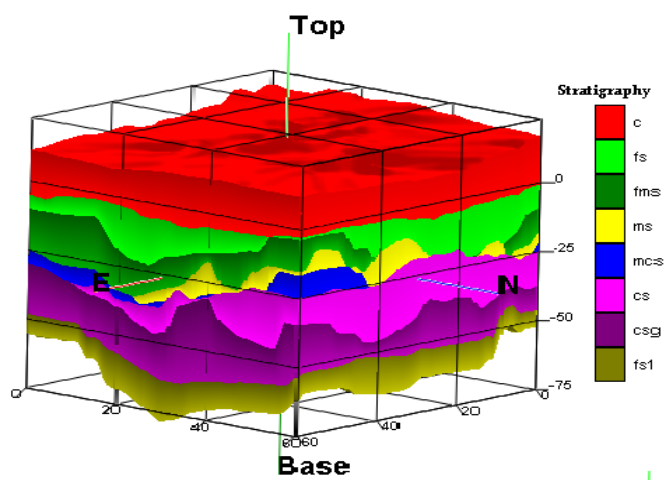

Fig.7 3D-stratigraphic view of the study area (Lateral distance in Km, Height in $\mathrm{m}$ );

View from north-east corner.

The sand formations in the sub-surface below the top clay is the only geologic formation could be used for groundwater exploration. In this work the sand formation is termed as composite sand formation because of the combination of different sandy formations of different grain sizes situated in different depth. The thickness of the composite sand formation has the great importance for the identification of favorable groundwater potential zone. In this regard, the three dimensional view of various sand formations along with the top clay of the investigated area is prepared.

\section{FENCE DIAGRAM}

The character and the nature of distribution of water bearing lithologic layer are the important criteria for identifying the groundwater potential zone. The stratigraphy describes the geometrical and age relation between the various lenses, beds and formations in geologic systems of sedimentary origin.

Lithological data have been used as an important source for hydrogeological investigation and subsurface formations distribution. The reliability of the information depends not only upon the accuracy of the data but also on the number of available sources. It is customary to present borehole lithologs in a vertical section so that the formation distribution as they actually occur would be reconstructed but it is not feasible to present effectively all the vertical section in a single diagram. The subsurface geology of the area investigated has been studied up to $91.44 \mathrm{~m}$ on the basis of lithological logs covering the whole area. The stratigraphic fence diagrams with and without cross-sectioning of the area are presented in Fig.8. The fence diagrams are extremely useful in predicting three dimensional distribution of the subsurface formation. This diagram represents an overall view of the subsurface geological formation delineating the major aquifer zones.

The area consists of seven subsurface layers. Every layer does not exist at a certain litholog point at a time. There are some places where fine sand is absent. Similarly, fine medium sand and the rest of all other sandy layers are absent in various places but not simultaneously. In a word, discontinuity of similar layers is observed in the investigated area. But the top clay layer exists everywhere in the entire part of the study area. No impermeable bed below the sand layers is identified from the borehole information, i.e., the thickness of the composite sand layer is still undetermined.

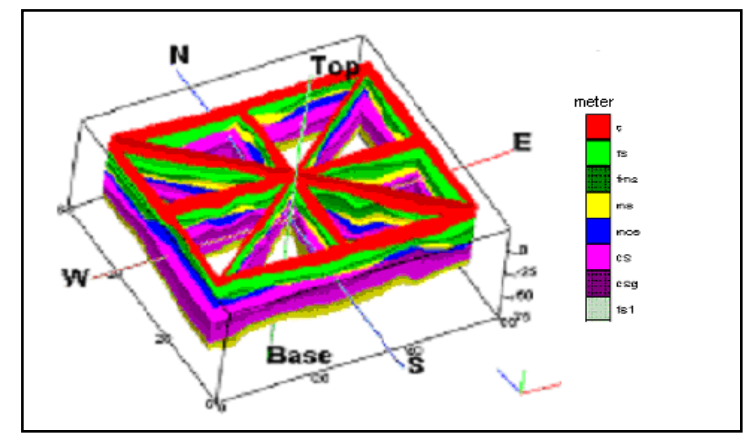

(a) With internal sectioning.

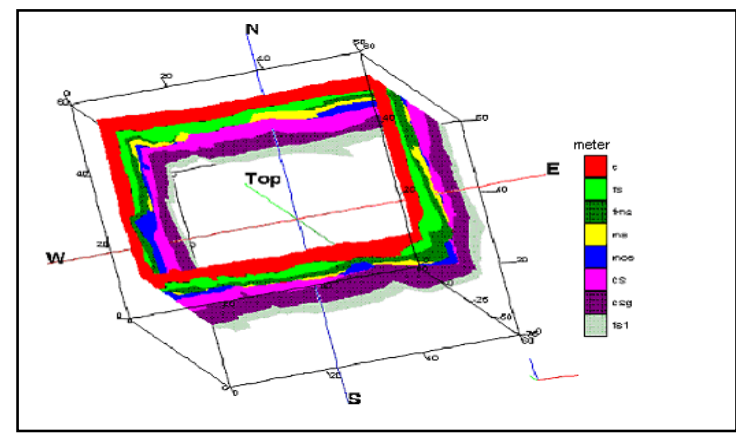

(b) Without internal sectioning.

Fig. 8 Fence diagram of the study area 


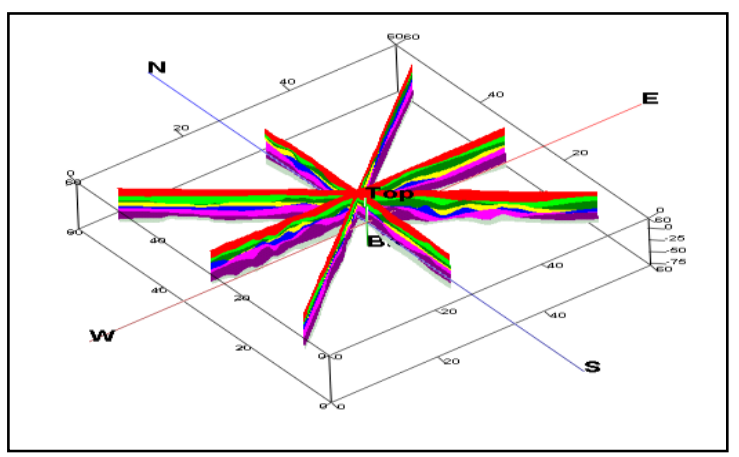

(a) View from west-south corner.

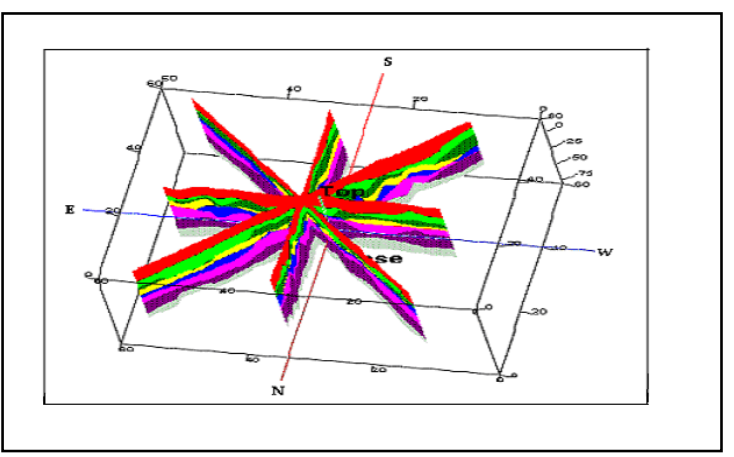

(b) View from north-east corner.

Fig.9 Formation variation along different directions

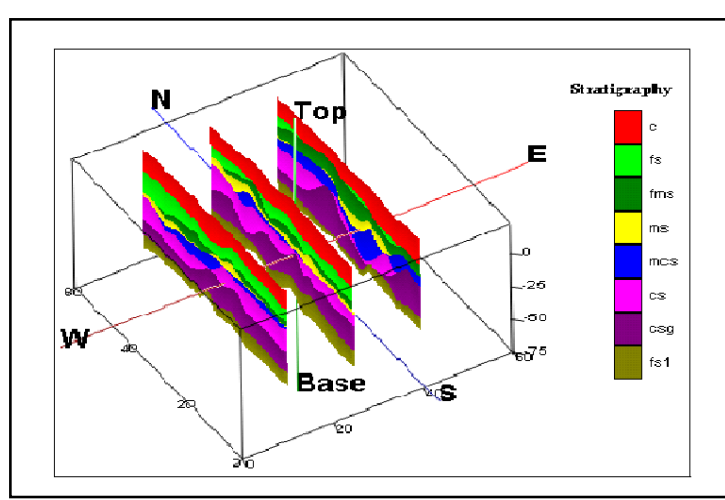

(a) View from north-south direction.

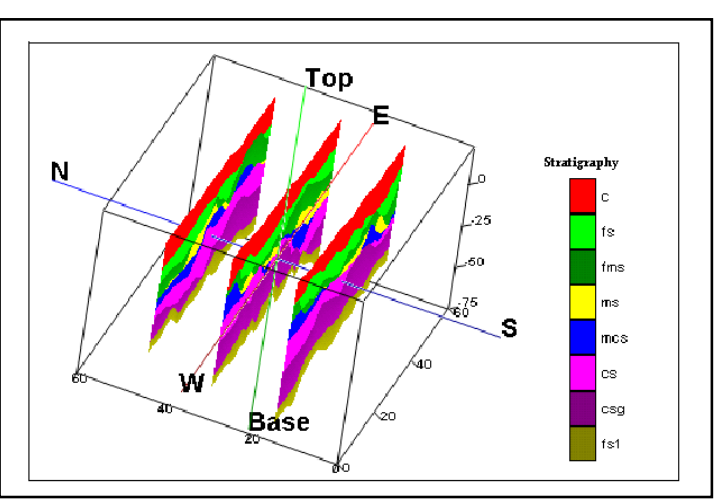

(b) View from east-west direction.

Fig. 10 Cross-sectional views in various directions

In the prepared fence diagrams, top clay of varying thickness is clearly observed. The maximum thickness of clay layer is $36.58 \mathrm{~m}$ which was recorded at Raghunathpur of Santhia upazilla. A minimum thickness of clay bed of $2.43 \mathrm{~m}$ is observed at Patirajpur of Ishurdi upazilla. So the investigated area mainly consists of two types of geologic formations where all the sandy layers of different grain size are counted below the common top clay. The only water bearing formation is that composite sand beds in the fence diagram. However, the favorable thickness of this bed is observed in all the parts of the study area. Lithological sectioning in different orientations have also been prepared and displayed in Fig.9 and Fig.10.

From the overall discussion of the fence diagram it could be concluded that the subsurface geology is favorable for groundwater exploration in small scale if the other conditions are satisfied. It is also mentionable that the usable aquifer of the area investigated is unconfined in nature. For large scale abstraction of groundwater continuous monitoring of annual discharge, recharge and balance must be considered, otherwise, ecological imbalance would affect the environmental system.

\section{Conclusion}

The subsurface formations of the study area have been studied from borehole litholig data. Seven distinct hydrostratigraphic layers have been identified in accordance of its vertical distribution and lithological composition. The physical and geometrical change of different layers in different parts of the area has also been observed. To observe the vertical distribution of different geologic formations in different parts of the area three dimensional stratigraphic views are prepared to visualize the subsurface of the study area. Stratigraphic crosssectional views along different directions are also prepared and displayed. From the analysis it can be concluded that the south-eastern side and some portions of Atghoria, Faridpur, Chatmohor and Ishurdi upazillas of the study area are potential for groundwater abstraction. Geologically it is suitable for groundwater exploration. But for large-scale abstraction sites should be selected consciously.

From the observation it is found that a top clay layer of varying thickness is clearly observed all over the area. All the sandy layers of different grain size are counted below the common top clay layer. The only sandy formation is used as groundwater source. The overall thickness of the composite sandy formation is suitable for groundwater potentiality. No other impermeable layer is found below the sandy formation. Basically, the area is unconfined in nature. 


\section{Acknowlegement}

The research work has been accomplished in the Geophysics Laboratory of the Department of Applied Physics and Electronic Engineering of Rajshahi University with the full co-operation of the institution of 'Panasi Project' under the department of Bangladesh Agriculture Development Corporation (BADC), Pabna, Bangladesh and the direct supervision of my guide who is appointed for this research work. I am very much grateful to the stated institution for giving us relevant information about the work.

\section{References}

[1]. Clark, L.,1988, Water Wells and Boreholes, Open University Press, Milton Keynes, New York, P.112.

[2]. Patra, K.C.,2001, Hydrology and Water Resources Engineering, Narosa Publishing House, New Delhi, India, P.228.

[3]. Todd, D.K., 1980, Groundwater Hydrology, John Wiley and Sons, New York, P.434.

[4]. Zilla Unnayan Porikkama, Pabna, 2005, Mass Communication Department, Ministry of Information, B.G. Press, Dhaka. P.18. 